\title{
"Os alunos teriam que estudar para poder comprar comida": a escola guarani como necessidade, obrigação e direito
}

CARLOS MAROTO GUEROLA

Universidade Federal de Santa Catarina, Florianópolis, SC, Brasil

\section{RESUMO}

O presente trabalho busca problematizar a visão ocidental de educação enquanto direito humano universal, contrapondo-a às reivindicações guarani à escolarização enquanto direito intercultural. O trabalho parte de uma fundamentação teórica que discute a deslegitimação e o silenciamento das populações indígenas em virtude de suas diferenças em relação ao padrão de experiência e conhecimento ocidentais, assim como a relação dessa deslegitimação e silenciamento com a imposição da necessidade e obrigação universais à escolarização. Com base em uma metodologia de pesquisa qualitativa de cunho etnográfico, são interpretados discursos que servem de insumos para caracterizar o direito intercultural guarani à escolarização, assim como as funções, responsabilidades e práticas de conhecimento que cabem à educação escolar diferenciada guarani do ponto de vista dos professores indígenas da escola da comunidade do Tekoa Itaty, ou aldeia do Morro dos Cavalos (Palhoça/SC).

guarani; educação escolar indígena; direitos humanos. 


\title{
"STUDENTS WOULD HAVE TO STUDY TO BE ABLE TO BUY FOOD": GUARANI SCHOOLING AS NEED, RIGHT AND DUTY
}

\begin{abstract}
This paper aims at questioning the Western view on education as a universal human right, contrasting it to the Guarani demand for schooling as an intercultural right. It departs from a literature review that discusses the delegitimization and silencing of indigenous populations on grounds of their differences from the Western standard of experience and knowledge, insofar as it discusses the bond between this delegitimization and silencing and the imposition of the universal needs and obligation to schooling. On the basis of an ethnographic qualitative research methodology, discourses are interpreted to serve as income to describe the Guarani intercultural right to schooling, as well as the roles, responsibilities and knowledge practices assigned to Guarani differentiated schooling by the indigenous teachers of the school of Tekoa Itaty or Morro dos Cavalos village (Palhoça, Santa Catarina, Brazil).
\end{abstract}

KEYWORDS

Guarani; indigenous schooling; human rights.

\section{“LOS ALUMNOS TENDRÍAN QUE ESTUDIAR PARA PODER COMPRAR COMIDA": LA ESCUELA GUARANI COMO NECESIDAD, OBLIGACIÓN Y DERECHO}

\section{RESUMEN}

Este trabajo busca problematizar la visión occidental de educación como derecho humano universal, contrastándola con las reivindicaciones guaraní a la escolarización como derecho intercultural. El trabajo parte de una fundamentación teórica que discute la deslegitimación y el silenciamiento de las poblaciones indígenas en función de sus diferencias en relación al modelo de experiencia y conocimiento occidental, así como la relación de esta deslegitimación y silenciamiento con la imposición de la necesidad y obligación universales a la escolarización. Con base en una metodología de investigación cualitativa de cuño etnográfico, se interpretan discursos que sirven como base para caracterizar el derecho intercultural guaraní a la escolarización, así como las funciones, responsabilidades y prácticas de conocimiento que competen a la educación escolar diferenciada guaraní desde el punto de vista de los profesores indígenas de la escuela de la comunidad del Tekoa Itaty, o aldea Morro dos Cavalos (Palhoça, Santa Catarina, Brasil).

PALABRAS CLAVE

guaraní; educación escolar indígena; derechos humanos. 


\section{PROBLEMATIZANDO O DIREITO À EDUCAÇÃO}

Nestes últimos quatro anos de trabalho junto às comunidades indígenas de Santa Catarina - Kaingang, Laklanõ-Xokleng e, principalmente, junto aos Guarani -, muito tenho aprendido a respeito da educação. Tanto que minha visão sobre $o$ assunto tem se transformado de maneira radical, orientando-se em direção a horizontes impensáveis anos atrás. Para nós, ocidentais, brancos, não indígenas juru'a kuery, nos termos guarani —, a educação — dizemos — é um direito humano, um direito inalienável a cada ser nascido neste planeta pelo fato de ser humano.

Isso significa que, ao considerarmos que a educação é algo que tem que ser reconhecido e garantido a todo ser humano pelo fato de ser humano, consideramos também que é possível que um ser humano não tenha reconhecida e garantida a sua educação, isto é, que alguém viva ineducado, desprovido de educação. Mas é possível a um ser humano viver sem educação, ser ineducado?

Entendamos educação aqui de forma abrangente, identificando-a, por exemplo, com a noção foucaultiana do exercício do poder, aquele que "opera no campo de possibilidade onde se inscreve o comportamento dos sujeitos ativos" (Foucault, 1995, p.243). Assim, se identificarmos educação com a modificação de comportamentos, atitudes e representações de um ser pela ação direta ou indireta de outro sobre as suas ações, conduzindo suas condutas e ordenando a probabilidade delas (Foucault, 1995), poderemos admitir que apenas pode ser considerado ineducado um ser humano completamente alheio a relações com outros seres que pudessem, pela ação direta ou indireta de suas ações, modificar suas condutas. Convenhamos no caráter incomum desses casos. Que sentido teria, então, dizer que os estados e governos têm que garantir o direito humano a termos nossas condutas conduzidas pela ação do outro, se isso é algo em grande medida inevitável desde o nosso nascimento?

Nenhum. Nós, ocidentais, quando falamos que alguém não tem o seu direito reconhecido ou garantido à educação, estamos dizendo, por via de regra, que esse sujeito não está tendo instrução formal ou escolarização. Isso graças à automática identificação que as redes de significação ou metanarrativas que conformam o que chamamos de nossa cultura (Geertz, 1973; Heath e Street, 2008) fazem entre os conceitos de educação e escola. Assim, nossa forma de conceber a educação nos faz entender que aqueles que não frequentam ou frequentaram a escola são seres carentes de educação, carentes da garantia de um direito que lhes seria inalienável por serem eles humanos e necessário para alcançar a completude de sua humanidade.

Porém, trabalhando e pesquisando junto aos Guarani, ouvindo o que têm a dizer sobre escola, aprendi que educação, nos moldes em que nós, ocidentais, a identificamos com a escolarização, é na verdade, para esse grupo, mais uma obrigação humana que um direito. Isto é, a educação é reivindicada por eles como um direito não por ser a escola um elemento positivo em si mesmo, que complete a sua humanidade, longe disso, mas sim porque hoje em dia ela é imprescindível, uma vez que a conjuntura econômica em que são obrigados a viver faz com que precisem da escola e dos conhecimentos nela veiculados. Essa necessidade torna a escola uma obrigação, pois sem essa instituição não há chances de futuro, obrigação esta que complementa a obrigação à educação, que já é imposta por lei a todos os brasileiros. 
Eis então o objetivo deste trabalho: problematizar a visão ocidental de educação enquanto direito humano universal, contrapondo-a à visão guarani sobre a escola enquanto direito humano intercultural. Para tanto, trago um recorte de minha dissertação de mestrado, intitulada $\grave{A}$ s vezes tem pessoas que não querem nem ouvir, que não dão direito de falar pro indígena: a reconstrução intercultural dos direitos humanos linguísticos na escola Itaty da aldeia guarani do Morro dos Cavalos (Guerola, 2012), na qual busquei contribuir para a discussão acerca da reconstrução intercultural (Sousa Santos, 2010) ${ }^{1}$ dos direitos humanos linguísticos escolares dos Guarani da Escola Indígena de Ensino Fundamental Itaty (doravante, EIEF Itaty), da aldeia do Morro dos Cavalos, ou Tekoa Itaty, localizada no município de Palhoça, Santa Catarina. ${ }^{2}$ As reflexões que os professores guarani do Morro dos Cavalos trouxeram em relação ao papel da escola na comunidade, assim como em relação à escola enquanto necessidade, obrigação e direito, constituem insumos ímpares para problematizar o silenciamento que seus discursos sofrem em decorrência do pensamento abissal (Sousa Santos, 2010), que lhes nega legitimidade e faz com que muitas pessoas não queiram nem ouvir e não deem direito de falar para o indígena.

Antes de aprofundar a discussão teórica e a análise de dados, apresento a seguir, ainda que brevemente, o contexto de pesquisa deste trabalho: as comunidades guarani de Santa Catarina e, especificamente, a comunidade guarani do Morro dos Cavalos.

\section{O MORRO DOS CAVALOS E AS ALDEIAS GUARANI EM SANTA CATARINA}

Como parte de seu território tradicional, os índios guarani ocupam o litoral do atual estado de Santa Catarina desde, no mínimo, o início do segundo milênio (Litaiff e Darella, 2000). É muito provável que a Ilha de Santa Catarina fosse a primeira parte desse litoral a ser despovoada pelos Guarani, que dela fugiram para o continente. Há registros tanto do despovoamento da ilha quanto menções à localidade de Viasa, ou Viaça, hoje denominada Massiambu (onde atualmente há uma aldeia guarani de mesmo nome, limítrofe à aldeia do Morro dos Cavalos), como local de habitação guarani já no século XVI (Litaiff e Darella, 2000). Ao todo, calcula-se que, no início do século XVII, a população indígena no litoral de Santa

1 Para Sousa Santos (2010, p. 67), a "reconstrução intercultural dos direitos humanos" consiste na emergência — por meio de "diálogos transfronteiriços sobre preocupações isomórficas" - de noções de direitos humanos com "competência global e legitimidade local", isto é, direitos que estejam situados nos contextos sociopolíticos e econômicos das comunidades a que dizem respeito (legitimidade local), mas que possam servir como orientação para outros coletivos ou comunidades (competência global).

2 A pesquisa de campo que deu lugar a Guerola (2012) foi desenvolvida entre 2011 e 2012, com base em uma abordagem qualitativa de cunho etnográfico, inserida na área da linguística aplicada e desenvolvida valendo-se da observação participante das aulas e do cotidiano da escola, assim como da gravação de entrevistas semiestruturadas com os cinco professores guarani da escola. 
Catarina era de cem mil pessoas, conforme indicam relatos da época (Santos, 1989 apud Vieira, 2006).

Em conjunto, os Guarani ocupam hoje terras entendidas como dentro dos limites geopolíticos do Brasil, Argentina, Paraguai, Uruguai e Bolívia. No Brasil, em virtude das diferenças de ordem linguística, principalmente, foram classificados por Schaden (1974) em três subgrupos distintos: Mbya, Nhandeva, ou Xiripa, e Kaiowa. De acordo com dados de Ladeira (2003), enquanto os Kaiowa encontram-se localizados no sul do Mato Grosso do Sul, com algumas famílias em aldeias próximas às Mbya no litoral do Espírito Santo e Rio de Janeiro, Guarani Mbya e Xiripa predominam na faixa litorânea do Espírito Santo até o Rio Grande do Sul, sendo que, entre eles, os Mbya passaram a prevalecer numericamente, embora em algumas aldeias sejam bastantes os descendentes de casamentos mistos entre membros dos dois subgrupos (Rosa, 2009).

Esses grupos familiares, Mbya e Xiripa, que têm procurado historicamente formar seus assentamentos na Mata Atlântica, ocupavam, nas regiões Sul e Sudeste do Brasil, cerca de cem áreas no início deste século (Ladeira, 2003). Nas terras do atual estado de Santa Catarina, estima-se a presença de cerca de 1.700 Guarani Xiripa e Guarani Mbya, distribuídos em 21 aldeias no litoral e no interior do estado (Brighenti, 2012). Além da população guarani, atualmente, no estado de Santa Catarina, encontram-se os grupos Laklanõ-Xokleng e Kaingang. Os três grupos constituem um contingente total de cerca de 10.400 indígenas, que residem em 29 terras indígenas (Brighenti, 2012).

Apesar de melhoras nas condições de vida desses grupos após as significativas mudanças jurídicas acontecidas a partir da promulgação da Constituição Federal de 1988, como o reconhecimento de várias demarcações de terras indígenas na faixa litorânea de Santa Catarina, o presente ainda está longe do futuro que os Guarani imaginam para si. Por constituírem uma população minoritária etnicamente diferenciada, sofrem constantes pressões e tentativas de controle de suas dinâmicas sociais e territoriais (Ladeira, 2003), encontrando-se "ainda hoje em situações e contextos de pressão advindos da sociedade envolvente, seja nacional ou regional", vivendo muitos deles em situações de miséria (Litaiff e Darella, 2000, p. 11).

A ocupação guarani da região do Morro dos Cavalos, na Enseada do Brito, no município de Palhoça/SC, nunca se delimitou à área restrita às moradias hoje existentes, uma vez que o local de residência atual se configurou após as obras de construção da rodovia BR-101, na década de 1960 (Litaiff e Darella, 2000). Essa década foi especialmente significativa para a comunidade guarani do Morro dos Cavalos, pois, como afirma Ladeira (2002, p. 2), eles

[...] sofreram o que consideram como primeira invasão em sua área, a construção [...] da rodovia BR-101, que cortou suas áreas de uso, antes contíguas. O crescimento da ocupação na região do entorno, a despeito da criação do Parque Estadual da Serra do Tabuleiro em 1975, o que também foi um agente cerceador do uso tradicional indígena, provocou a redução dos espaços ocupados pelos Guarani, comprometendo a sua autonomia econômica e a satisfação de suas necessidades. 
Além desses impactos, a construção do traçado original da rodovia BR-101 motivou também a "descoberta institucional"(Litaiff e Darella, 2000, p. 4) dos índios guarani na região do Morro dos Cavalos.

A respeito da situação fundiária, a Portaria Declaratória da Terra Indígena Morro dos Cavalos (doravante, TI) foi publicada pelo Ministério da Justiça no Diário Oficial da União em abril de 2008. Atualmente é aguardada a desintrusão total da terra, assim como a sua homologação. ${ }^{3}$ A luta pela demarcação da TI tem se visto permeada por uma agressiva campanha midiática contra a demarcação, com matérias com títulos tais como "Made in Paraguai - A FUNAI tenta demarcar área de Santa Catarina para índios paraguaios, enquanto os do Brasil morrem de fome”, publicada na revista Veja em março de 2007, e outras publicadas ou televisionadas por empresas como a RBS, ${ }^{4}$ tais como a série "Morro dos Cavalos: uma montanha de problemas em discussão", divulgada em outubro de 2013. Essa campanha tem enrijecido o atrito entre as comunidades envolvidas no conflito, o que tem derivado em agressões verbais e por vezes físicas contra a comunidade guarani.

Com 1.988 hectares, na TI Morro dos Cavalos habitam hoje aproximadamente 32 famílias, com uma população total em torno de 190 pessoas. O sustento econômico da comunidade depende principalmente da confecção de artesanato e de sua venda em centros urbanos, do trabalho assalariado ou de bolsas de estudo de alguns membros da comunidade, além da ajuda de programas governamentais de assistência social, como distribuição de cestas básicas, Programa Bolsa Família, benefício de previdência social, entre outros.

Após essa breve contextualização, apresento na seção seguinte a fundamentação teórica deste trabalho, na qual busco problematizar a universalidade do direito humano à educação/escolarização à luz da problematização da "universalidade radicalmente excludente" (Lander, 2005b, p. 10) do ocidentalismo hegemônico e seu totalitarismo epistêmico científico (Mignolo, 2004), assim como à luz do silenciamento das populações subalternizadas em que essa universalidade totalitária assenta sua hegemonia.

\section{EPISTEMOLOGIA, CONHECIMENTO, ESCOLA: A UNIVERSALIDADE RADICALMENTE EXCLUDENTE}

Souza (2010), em sua leitura de autores como Bakhtin (1981), Tedlock e Mannheim (1995), Foucault (1996) ou Howard-Malverde (1997), ressalta a emer-

3 Para saber mais sobre a situação fundiária da TI Morro dos Cavalos e sobre seu processo demarcatório, ver Cronologia da luta pela demarcação da Terra Indígena Morro dos Cavalos - fatos relevantes. Duas décadas de espera (1993-2013), elaborada pela Comunidade Guarani Itaty/Morro dos Cavalos et al. Palhoça, Florianópolis, 19 mar. 2013. Disponível em: <http://www.abant.org.br/file?id=1053>. Acesso em: 6 abr. 2015.

4 "Uma das maiores empresas de comunicação multimídia do Brasil e maior afiliada da Rede Globo [...] líder na área de comunicação no Rio Grande do Sul e em Santa Catarina”. Disponível em: <http://www.gruporbs.com.br/quem-somos/o-grupo-rbs/>. Acesso em: 13 abr. 2015. 
gência e a performatividade das práticas de conhecimento, ${ }^{5}$ nas quais é construído o significado por meio da linguagem. Essas características são abstraídas do fato de o significado ser produzido, apropriado e modificado pelos interlocutores das práticas, na fronteira entre um eu e um outro. A emergência e a performatividade da sua construção negam essência ao significado, pois ele é socialmente situado e está em constante (re)constituição (Souza, 2010). As práticas de conhecimento pelas quais emerge o significado envolvem participantes em "estratégias de posicionamento de uns com os outros" (Howard-Malverde, 1997 apud Souza, 2010, p. 295), interligadas às relações de poder estabelecidas entre eles. Nessa visão, o nível epistemológico fundamental do conhecimento "é constituído pelas interações comunicacionais no quadro das práticas sociais dos agentes linguísticos humanos"(Crépeau, 2001, p. 26).

Essa forte ligação entre a construção do significado e o pertencimento sócio-histórico dos participantes das práticas de conhecimento "recusa a normatividade universal e a crença em verdades universais e não sócio-históricas que sirvam para fundamentar de forma 'objetiva' - isto é, atemporal e não social - leituras 'certas' ou 'erradas"' (Souza, 2011, p. 117). Citando Vattimo (2004), Souza (2011, p. 114) conclui que "as verdades e os fundamentos próprios são produtos das comunidades às quais pertencemos e de sua história".

Contudo, as economias políticas ou políticas gerais de verdade (Foucault, 200-?) da sociedade global fazem com que apenas alguns dos significados e conhecimentos gerados nas interações comunicacionais no quadro das práticas sociais sejam reconhecidos como verdades, como significados e conhecimentos legítimos, universais, fundamentados na razão, produzidos dentro do raciocínio científico e objetivo. Esse reconhecimento e legitimação se dá em virtude da forma em que as verdades são enunciadas, forma que se encontra imanentemente ligada às comunidades, posições e origens sócio-históricas específicas dos agentes linguísticos que as enunciam.

Dentro dessa perspectiva, a reconstrução intercultural dos direitos humanos embasa-se no questionamento da universalidade que a tradição ocidental hegemônica atribui aos seus próprios significados e padrões de conhecimento e experiência (Sousa Santos, 2010). Na visão de Lander (2005b), o caráter universal do conhecimento ocidental constrói-se a partir da própria experiência particular do ocidentalismo, que é a única base com que essa tradição interpreta a totalidade da experiência humana. A parcialidade dessa interpretação constitui, assim, uma "universalidade radicalmente excludente" (Lander, 2005b, p. 10).

A interpretação ocidentalista da totalidade da experiência humana exclusivamente a partir da própria experiência particular encontra seu fundamento nos imaginários de civilização e de barbárie (Castro-Gómez, 2005). Com base nisso, o padrão ocidental universal estabelece uma monocultura do tempo linear (Sousa Santos, 2004, 2010), isto é, uma hierarquia cronológica na qual a sociedade ocidental é definida como a mais civilizada, desenvolvida e superior. Nes-

5 Concordo com Sousa Santos (2004, p. 805), em que "é evidente que todas as práticas sociais envolvem conhecimentos e, nesse sentido, são também práticas de saber". Nessa perspectiva, virtualmente todas as práticas sociais constituem práticas de conhecimento. 
sa linha, muitos dos grandes pensadores e teóricos sociais europeus coincidiram na opinião de que a espécie humana vai desenvolvendo-se por meio dos mesmos estágios de aperfeiçoamento, saindo progressivamente da ignorância até "obter a maioridade a que chegaram as sociedades modernas europeias" (Meek, $1981 \mathrm{apud}$ Castro-Gómez, 2005, p. 84). O primeiro estágio na escala de desenvolvimento humano, para essa tradição, é exemplificado nas sociedades indígenas americanas, tal qual foram descritas por cronistas e viajantes europeus, no seu "estado de natureza" (Castro-Gómez, 2005, p. 84), a partir do qual todas as populações progrediriam "no tempo de acordo com leis universais inerentes à natureza ou ao espírito humano" (Castro-Gómez, 2005, p. 84).

As "diferenças incomensuráveis" (Quijano, 1999 apud Castro-Gómez, 2005 , p. 83) entre os povos, classificados de acordo com a hierarquia cronológica de estágios de progresso, legitimam a sua espoliação, pois a política justa em relação aos povos considerados menos evoluídos seria fazê-los progredir pela sua completa ocidentalização (Castro-Gómez, 2005). Essas diferenças incomensuráveis servem como base para que o pensamento abissal (Sousa Santos, 2010) desqualifique e deslegitime as experiências e conhecimentos desses povos, tornando-os invisíveis, ininteligíveis ou descartáveis (Sousa Santos, 2004), excluídos no "outro lado da linha", isto é, no "reino do impensável na modernidade ocidental” (Sousa Santos, 2010, p. 49). O imaginário do progresso surge, assim, "de vozes escutadas ou apagadas, de memórias compactas ou fraturadas, de histórias contadas de um só lado, que suprimiram outras memórias" (Mignolo, 2005, p. 37-38).

O silenciamento da experiência e significados dos povos desprivilegiados pela monocultura do tempo linear tem repercussões diretas na sustentação da epistemologia ocidental como modelo universal de ciência. Servindo também à dominação epistemológica, a monocultura do tempo linear favorece o estabelecimento de relações extremamente desiguais entre os diferentes conhecimentos das tradições colocadas no topo e na base da hierarquia cronológica por ela estabelecida (Lander, 2005a).

Esses conhecimentos hierarquizados chegam a constituir-se em "conhecimentos rivais" (Sousa Santos e Meneses, 2010, p. 16), isto é, conhecimentos díspares com critérios de validade distintos e a serviço de interesses divergentes e muitas vezes conflitantes. No caso da epistemologia ocidentalista, esta tem sido construída com base nas necessidades da dominação capitalista e colonialista, e o conhecimento a que atribui legitimidade e verdade possibilita intervenções no mundo real que favorecem essa dominação (Sousa Santos, 2010). Negando esses interesses, por meio de seu totalitarismo científico (Mignolo, 2004), tal epistemologia arroga-se a exclusividade da geração de conhecimento neutro sobre a realidade objetiva, aquela que seria, necessariamente, "a mesma para todos os homens, já que ela é independente do sujeito que a observa" (Durkheim, 1981 apud Crépeau, 2001, p. 12).

Cegos por esse totalitarismo epistêmico, os Estados-nação europeus, complementando a ação de suas igrejas, desenvolveram mecanismos institucionais de perpetuação e divulgação dos conhecimentos legitimados por suas políticas gerais 
de verdade. A tradição ocidental hegemônica escolarizou o conhecimento científico universal e, mais recentemente, tem buscado universalizar a instituição por meio da qual propõe garantir o direito e a obrigação dos grupos subdesenvolvidos a tal conhecimento. Nessa linha, a Declaração Universal dos Direitos Humanos, ${ }^{6}$ adotada pela Assembleia Geral das Nações Unidas em 1948, estabeleceu em seu artigo XXVI que "toda pessoa tem direito à instrução", direito cujo reconhecimento veio acompanhado do reconhecimento da sua obrigatoriedade "A instrução elementar será obrigatória”). No Brasil, do mesmo modo, a Constituição Federal de 1988, em seu artigo 207, estabeleceu o direito à "educação básica obrigatória e gratuita dos quatro aos dezessete anos de idade" (Brasil, 1988).

Porém, ao longo de toda a história da escola, mas principalmente depois da sua progressiva universalização pós-Revolução Industrial, a relação de inúmeros povos com essa instituição tem sido árdua e conflitante. No caso das comunidades indígenas no Brasil, a instituição escolar e os seus conhecimentos universais têm estado tradicionalmente a serviço da catequização e do aniquilamento cultural, com papel preponderante da Igreja, estabelecendo relações de submissão e de dominação, impondo a língua portuguesa em detrimento das línguas ameríndias e promovendo a integração dos índios à comunidade nacional por meio de instituições governamentais - como o Serviço de Proteção ao Índio (SPI), ou a Fundação Nacional do Índio (FUNAI) - e não governamentais - como o Summer Institute of Linguistics (SIL) etc. (Hentz, 2013; Leite, 2008; Souza, 2009).

Como notou Litaiff (1996, p. 33), entre os Guarani, a presença da "escola do branco" conseguiu gerar "graves crises de identidade, e até suicídios". No livro Educação e sociedades tribais, Santos (1975) descreveu em profundidade a escolarização das comunidades indígenas por meio das escolas dos postos indígenas do SPI, e da FUNAI posteriormente, no sul do Brasil. Esse autor reconheceu o papel da escola como instrumento estratégico para a garantia da submissão e diluição dos índios na sociedade nacional e como veículo de dominação pelo qual os integrantes das camadas dominantes se convenceriam "de que os indígenas estão sendo adequadamente cuidados e que 'se mais não aproveitam é porque não querem ou são incapazes"' (Santos, 1975, p. 55). A escola em contextos indígenas, "desconectada do real", conseguia a submissão das comunidades "pelo inculcamento em seus membros de situações que acabam por levar à conclusão da complexidade do mundo dos brancos e à consequente incapacidade do indígena em compreendê-lo" (Santos, 1975, p. 62).

Tal escola, patrocinada e inspirada pela sociedade dominante, procurava assegurar, em primeiro lugar, os objetivos dessa sociedade e, assim, representava o domínio do mundo dos brancos pelo ensino da língua portuguesa, da preparação de contingentes para ocupar empregos precários no mercado de trabalho regional, da formação de consumidores e da disseminação de estereótipos (Santos, 1975).

6 Disponível em: $<$ http://www.ohchr.org/EN/UDHR/Documents/UDHR_Translations/ por.pdf $>$. Acesso em: 10 abr. 2015. 
Todavia, a escola hoje, para os indígenas em geral, e para os Guarani no caso que nos ocupa, resulta como obrigação humana também de uma necessidade. Historicamente, a ação indigenista do estado brasileiro — como assegurou Santos (1975) a respeito dos postos indígenas — tem visado à aculturação econômica dos índios ao sistema capitalista. A ação da sociedade envolvente sobre o ambiente e a natureza, concomitantemente, tem restringido cada vez mais os recursos a que as comunidades indígenas têm acesso, tornando a sua economia impraticável. A escola torna-se, então, um instrumento indispensável para se ter acesso aos saberes por meio dos quais é possível garantir a subsistência em um sistema econômico alheio, em relação ao qual os povos indígenas encontram-se subjugados.

Como afirma Santos $(1975$, p. 31), "é no sistema de produção e consumo que melhor se percebe a submissão dos indígenas aos interesses da sociedade envolvente". Esse autor soma à falta de recursos a inteira substituição da tecnologia que permitia aos grupos indígenas a exploração da natureza para sua sobrevivência e a obrigação desses grupos de destinar a maior parte do seu esforço de trabalho para atender interesses da sociedade nacional como obstáculos para esses povos se dedicarem às atividades de sua economia tradicional.

Reféns desse sistema, as comunidades guarani em Santa Catarina encontram-se hoje em uma situação de extrema dependência econômica em relação à sociedade dominante, ao Estado brasileiro e à economia de mercado neoliberal. Isso se deve ao fato de, do mesmo jeito que os postos indígenas escondiam "verdadeiras empresas, dedicadas à produção e ao lucro"(Oliveira, 1972 apud Santos, 1975 , p. 39), a política indigenista tradicional no sul do Brasil ter escondido uma visão empresarial que buscava "utilizar o indígena em seu potencial de produção e consumo, além do seu patrimônio, como instrumentos de prática de desenvolvimento interno" (Santos, 1975, p. 39).

Os Guarani, cuja própria economia não garante mais seu sustento, tornaram-se cada vez mais dependentes das determinações gerais que comandam a lógica da economia de mercado neoliberal, principalmente por não disporem de terra suficiente (Litaiff, 1996). Assim, em virtude das dramáticas condições de vida desse povo, da dependência da sociedade não indígena e dos seus bens de consumo, na década de 1990, a educação escolar começa a ser reivindicada pelas comunidades guarani, junto à demarcação de espaços próprios para sobreviver e existir (Vieira, 2006). Nesse sentido, a escola por si mesma passou a resolver parte do problema: ela é hoje fonte de renda para os professores, professoras e merendeiras guarani; auxilia e, por vezes, fornece quase exclusivamente a alimentação das crianças (Salvaro, 2009) e faz parte da contrapartida de programas de transferência direta de renda com condicionalidades, como o Bolsa Família, programa do governo federal brasileiro.

Nessa conjuntura, como veremos mais adiante na seção de análise de dados, a escola é reivindicada pelas comunidades indígenas como um espaço de prática e divulgação de suas tradições, conhecimentos e línguas, e como um espaço de entrada do conhecimento científico e quaisquer outros instrumentos provindos da sociedade envolvente passíveis de contribuir na sua luta pela sobrevivência. Essa reivindicação 
ilustra a lógica dos direitos humanos interculturais em contraposição aos direitos humanos entendidos como universais. ${ }^{7}$

Nesse sentido, Sousa Santos (2010) chama atenção para o caráter controverso do campo dos direitos humanos, pois as políticas a seu respeito estariam ainda hoje a serviço dos interesses econômicos e geopolíticos do capitalismo hegemônico. Embasada em um conjunto de pressupostos claramente ocidentais, e rascunhada sem a participação da maioria dos povos do mundo, a Declaração Universal dos Direitos Humanos proclamou "o ideal comum a ser atingido por todos os povos e todas as nações", para que, "através do ensino e da educação", medidas fossem adotadas para "assegurar o seu reconhecimento e a sua observância universais", tanto entre os Estados que a assinaram como "entre os povos dos territórios sob sua jurisdição" (Sousa Santos, 2010).

Destarte, o reconhecimento do direito desses povos a progredirem de acordo com o "ideal comum a ser atingido" implicou o descobrimento da pobreza massiva existente na Ásia, na África e na América Latina no período pós-guerra (Escobar, 1995 apud Lander, 2005b), que fora definida em relação ao padrão europeu. Tal descoberta transformou dois terços da humanidade em comunidades carentes, precisadas da intervenção de frentes de poder político e econômico nacionais e internacionais em prol da garantia dos direitos universais de "todos os povos e todas as nações", inclusive daqueles tradicionalmente silenciados, que não opinaram a seu respeito. Dessa forma, o estabelecimento de uma ordem de direitos universais de todos os seres humanos não significou outra coisa que o passo prévio "para exatamente negar o direito à maioria deles" (Lander, 2005a, p. 11).

Felizmente, ferramentas jurídicas hegemônicas como os direitos humanos podem ser utilizadas para objetivos não hegemônicos desde que a concepção que se tenha delas seja não hegemônica, isto é, uma concepção provinda das populações marginalizadas e silenciadas pelas concepções dominantes de tais ferramentas (Sousa Santos, 2003). Assim, o direito pode tanto ser autoritário como emancipador (Sousa Santos, 2004), do mesmo modo que a ciência ou a escola.

De forma congruente com essa afirmação, os dados etnográficos que apresento a seguir apontam, valendo-se da voz dos professores guarani, o modo como, na aldeia guarani do Morro dos Cavalos - assim como em muitos outros locais e comunidades violentamente incluídas na sociedade de mercado globalizada -, a ressignificação, partindo de uma perspectiva contra-hegemônica, de ferramentas como os direitos humanos ou a escola (e como, consequentemente, o direito humano à educação) resulta tão necessária quanto a sua perpetuação para fins de sobrevivência. Para muitas comunidades, torna-se necessário ressignificar — reimaginar, reinterpretar, reconstruir — os instrumentos de opressão tornando-os emancipadores, perpetuando-os para revertê-los. É esta, nas palavras de Mignolo (2004, p. 671), a única dissidência possível: "a dissidência 'dentro' dos próprios objetivos da modernidade".

7 Sousa Santos (2010, p. 67) afirma que, "se concebidos como universais, os direitos humanos sempre serão um instrumento da luta de ocidente contra qualquer conceição alternativa da dignidade humana que seja socialmente aceita em outra parte”. 


\section{A ESCOLA PARA OS GUARANI DO MORRO DOS CAVALOS}

A economia aqui é fazer artesanato ou trabalhar fora para poder comer, porque agricultura aqui não dá resultado [...] fazer uma lavoura aí que sustente toda a comunidade ou que cada um faça sua agricultura, sua roça, e que ele possa conseguir comer durante um ano, não existe isso, então, aí, a gente conversou nas reuniões que os alunos teriam que estudar para poder pegar emprego para trabalharem, para poder comprar comida, e outra questão também é esse negócio de problema de terra que [a gente] quase nem entende... A gente está chamando um juru'a de fora, tem que vir para cá para escrever um documento, para correr atrás de resolver esses problemas de terra, demarcação de terra, essas coisas mais burocrático aí. (Antunes, A., 2011)

Como é possível depreender das palavras do professor Adão Antunes, impossibilitados de praticarem sua própria economia pelos motivos que foram expostos nas seções anteriores, como falta de terra, tanto na dimensão quantitativa como qualitativa ("agricultura aqui não dá resultado", "fazer uma lavoura aí que sustente toda a comunidade ou que cada um faça sua agricultura [...] não existe isso"), os Guarani dependem hoje da economia de mercado para a sua subsistência ("A economia aqui é fazer artesanato ou trabalhar fora para poder comer"). Essa dependência da economia de mercado torna a escola uma ferramenta indispensável para se ter sucesso e bem-estar econômico ("os alunos teriam que estudar para poder pegar emprego para trabalharem, para poder comprar comida"). Do mesmo modo, em decorrência da falta de terra, a principal luta guarani, qual seja, a demarcação de terra ou a ampliação das áreas já demarcadas, é outro motivo econômico que fundamenta a necessidade de escola ("outra questão também é esse negócio de problema de terra”). Os Guarani querem que as futuras gerações estejam formalmente instruídas para se envolverem com sucesso na luta política e administrativa que envolve a demarcação de terra, de forma que não seja indispensável às comunidades a interlocução dos não indígenas nesses processos ("A gente está chamando um juru'a de fora [...] para correr atrás de resolver esses problemas de terra").

Contudo, a dispensabilidade dos não indígenas não é almejada apenas no que diz respeito à demarcação de terra, e sim a todos os outros âmbitos do universo econômico guarani. Para conseguir essa autonomia econômica e administrativa, a escola desempenha um papel fundamental:

O nosso objetivo é fazer com que tudo que nós precisava para trabalhar com essa burocracia sejam índios, futuramente até a saúde seja na mão dos índios, a escola, demarcação de terra, contabilidade, que sejam índios que trabalhem, então esse é o objetivo, preencher todas as vagas que são preenchidas por juru'a sejam preenchidas por índio [...] formar pessoas, para trabalhar aqui dentro da aldeia, e os que trabalharem fora, mas que tragam os resultados para dentro da aldeia. (Antunes, A., 2011) 
Os Guarani esperam que a sua escola forme membros da comunidade capazes de assumir as funções que - em decorrência do seu universo econômico ter sido sequestrado pelo universo econômico capitalista e suas instituições (escola, serviços de saúde, entre outras) - ainda hoje são exercidas por não indígenas, tanto dentro das comunidades ("formar pessoas, para trabalhar aqui dentro da aldeia") quanto nos âmbitos fora das aldeias com repercussão na vida dentro delas ("e os que trabalharem fora, mas que tragam os resultados para dentro da aldeia”). Para que essa formação seja o mais completa possível, muitos Guarani desejam dar continuidade aos estudos em instituições de ensino superior. Nesse sentido, a escola desempenha também um papel central para possibilitar que os Guarani, que assim o desejarem, possam ter acesso a esse nível de ensino.

O ano que vem [os alunos do ensino médio] se formam, com certeza eles vão estar procurando uma universidade... e meu medo é que eles vão para a universidade e sofram $[\ldots]$ porque hoje tenho colegas que estão junto com a gente lá na universidade que sofrem, sofrem, aí às vezes eles pensam até em desistir, porque eles não conseguem acompanhar [...] então, aí, depois disso a gente veio para cá e "vamos colocar eles então para ser do jeito que tem que ser", porque senão nós vamos perder o tempo deles estudar até aqui, chegar lá e não conseguir passar. (Antunes, E., 2011)

A professora Eunice Antunes, acadêmica do curso de licenciatura intercultural indígena do sul da Mata Atlântica da Universidade Federal de Santa Catarina ${ }^{8}$ à época da pesquisa, conhecedora de primeira mão das dificuldades que muitos de seus colegas atravessaram no curso ("tenho colegas [...] na universidade que sofrem [...] às vezes eles pensam até em desistir, porque eles não conseguem acompanhar"), mostra nesse trecho sua preocupação quanto aos alunos não chegarem o suficientemente preparados para poder afrontar o seu acesso e permanência no ensino superior. O papel da escola para tal fim é primordial a ponto de a professora Eunice considerar que, caso a escola não consiga preparar os alunos para encararem esse nível de ensino (tanto no acesso quanto na permanência, “meu medo é que eles vão para a universidade e sofram”), ela terá desperdiçado o tempo dos estudantes ("nós vamos perder o tempo deles estudar até aqui, chegar lá e não conseguir passar").

Essa formação em relação ao universo não indígena, da qual a escola guarani precisa prover os seus alunos, tem como objetivo e fundamento a defesa em relação a esse mundo não indígena que assedia as comunidades e impede, séculos a fio, a viabilidade dos seus próprios modos de vida. Contudo, como ilustra o depoimento a seguir, não é a preparação para a defesa em relação ao universo não indígena a única preocupação dos professores guarani em relação à escola:

8 Mais informação em: <http://licenciaturaindigena.ufsc.br/>. Acesso em: 9 abr. 2015. 
A gente se preocupa com [...] preparar eles para fora, e explicando todo assim, toda a educação deles assim, de que o estudo é bom para fazer isso, para você defender teu povo, para você buscar os nossos direitos, quando você se formar na faculdade, você vai para a faculdade, mas que você retorne para a aldeia [...] para ele se formar algum professional [...] mas também a gente se preocupa aqui dentro, com a educação deles também, com a cultura, a gente se preocupa para que não se perca nossa língua, nossa cultura, junto com os alunos sempre estar repassando toda essa dimensão de conhecimento. (Moreira, 2011)

O direito à escola está estreitamente vinculado à obrigação e à necessidade dessa instituição, uma vez que apenas a formação proveniente dela pode viabilizar a defesa dos direitos políticos, econômicos e culturais das comunidades pelos seus próprios membros. Estudar faz sentido, nessa perspectiva, apenas se servir para a defesa e busca dos direitos do povo guarani ("o estudo é bom [...] para você defender teu povo, para você buscar os nossos direitos"), do mesmo modo que estudar no ensino superior apenas faz sentido, aos olhos do professor Marcos Moreira, se os profissionais formados retornarem às aldeias e trabalharem para elas e dentro delas ("você vai para a faculdade, mas que você retorne para a aldeia"). Além da preparação "para fora", há a preocupação dos professores guarani trabalharem "dentro", isto é, trabalharem os conhecimentos relacionados à "educação" (aquela que era e ainda é aprendida à margem da escolarização e não é automaticamente identificada com ela) e à cultura guarani, no seu sentido mais abrangente ("nossa cultura, junto com os alunos sempre estar repassando toda essa dimensão de conhecimento").

O direito de se trabalhar com a cultura guarani dentro da escola está também ligado à necessidade, pois a espoliação da natureza nos entornos das aldeias, que inviabiliza a autonomia econômica guarani, alimenta o anseio de se trabalhar a autossustentabilidade das comunidades dentro da escola. Esse trabalho de sustentabilidade encontra-se intimamente ligado à noção abrangente de cultura e é também, de acordo com as palavras do professor Adão Antunes, uma atribuição de relevância para a escola.

O nosso objetivo de trabalho na escola é fazer, viver mesmo em comunidade, viver em aldeia, viver coletivamente [...] fazer lavoura coletivamente, fazer açude para criar peixe, criar abelha, tem todos os projetos para a gente trabalhar na sustentabilidade [...] plantar taquara em lugar desses pino aí [...] porque hoje em dia a taquara é a força da cultura, do artesanato, construção da casa, não existe quase mais taquara, está muito longe nos morros, lá muito longe, e para fazer uma casa dessa aí [indicando a opy (casa de reza) escolar] tem que fazer um serviço mais grande que fazer uma casa de madeira, ou de alvenaria, e então a gente não tem que perder esse foco da cultura. (Antunes, A., 2011)

A espoliação da natureza a que fiz menção é explicitada nas palavras do professor Adão na referência por ele feita à dificuldade para se encontrar um dos materiais de maior centralidade na arquitetura e no artesanato guarani: a taquara ("não existe quase mais taquara, está muito longe nos morros"). Essa dificuldade 
acaba provocando que seja mais fácil se adaptar à economia não indígena e aos seus materiais do que desenvolver a própria ("para fazer uma casa [com taquara] [...] tem que fazer um serviço mais grande que fazer uma casa de madeira, ou de alvenaria"). $\mathrm{Na}$ visão do professor Adão, a escola deve propiciar o trabalho de sustentabilidade dentro da escola tanto para fortalecer aquelas formas de economia em maior medida identificadas com a cultura guarani (e de peso substantivo na economia da comunidade, como o artesanato, "hoje em dia a taquara é a força da cultura, do artesanato") quanto para favorecer a própria filosofia e valores da economia guarani ("O nosso objetivo de trabalho na escola é fazer, viver mesmo em comunidade, viver em aldeia, viver coletivamente").

Para o professor Adão Antunes, o trabalho com a cultura dentro da escola não é apenas desejável, mas sim imprescindível para a sua manutenção. A escola desempenha, para ele, um papel fulcral contra o esquecimento da cultura:

Ao entrar na aula do professor Adão, leio no quadro um texto que ele recém acabou de escrever e que os alunos se dispõem a copiar:

Os Guarani, quer dizer, nós, os Guarani, somos uma das tribos mais unidas que existe, toda a comunidade com muitas coisas. As culturas guarani hoje a nova geração de Guarani não conhece bem a cultura guarani e por isso que nas escolas guarani é importante que os professores contem histórias sobre nossos antepassados, como eles caçavam e pescavam se não daqui a 50 anos os Guarani vão esquecer as histórias, mitos e a religião. (Nota de campo, 18 ago. 2011)

De acordo com o texto transcrito, na visão do professor Adão, caso as novas gerações guarani, desconhecedoras da própria cultura, não tenham acesso a ela dentro da escola, alguns dos seus elementos centrais, como "as histórias, mitos e a religião", serão esquecidos em médio prazo. Importa registrar aqui que o termo cultura, conforme usado por muitos professores e lideranças indígenas, condiz apenas parcialmente com a definição que foi fornecida no início deste texto de cultura como redes de significação ou metanarrativas, pois possui um significado extraordinariamente amplo, muitas vezes amalgamado ao conceito de tradição.

Nos depoimentos de todos os colaboradores da pesquisa, foram recorrentes as referências à cultura como objeto, usado em referência a um tempo passado. É à luz dessa perspectiva que é possível compreender os discursos a respeito da cultura como algo que é possível desconhecer ou perder ("hoje a nova geração de Guarani não conhece bem a cultura guarani", "a gente se preocupa para que não se perca [...] nossa cultura"). Não é objetivo deste trabalho discutir o significado do termo cultura no discurso indígena ou guarani, contudo, por seu caráter abrangente e, até certo ponto, ainda pouco problematizado e explorado dentro da pesquisa acadêmica sobre educação escolar indígena, mantenho-o em itálico, buscando assim evitar leituras fixas ou predeterminadas de seus significados.

Continuando na discussão a respeito do papel da cultura guarani no trabalho escolar para dentro, o seguinte depoimento é trazido aqui para mostrar como a falta dos ambientes próprios à economia guarani repercute na dificuldade de se aprender 
conforme a tradição da comunidade, assim como na necessidade de escola para superar tal dificuldade. Nele, Eunice sintetiza, igualmente, qual é para ela o papel da escola na formação dos alunos em relação aos mundos de fora e de dentro da aldeia:

Hoje aqui no Morro dos Cavalos [...] não tem um rio próximo para eles estar pescando, caça, não tem como, agricultura, piorou [...] então, para as crianças aqui do Morro dos Cavalos, crescer aprendendo a tradição é difícil [...] a escola aqui eu acho importante porque [...] nós, como professores, temos a obrigação de passar a parte cultural, que é a questão da religião, da tradição, [...] para ele estar sabendo que a nossa cultura é assim, e também estar preparando eles para esse mundo, essa globalização que vem muito rápido [...] é uma coisa assim que quando a gente percebeu já está na aldeia [...] sem perceber como é que veio [...] a escola é importante porque ela pode transformar isso, eu posso pegar o computador, criar um site para divulgar minha cultura, criar um $\mathrm{CD}[\ldots]$ e aí na parte que a gente pode estar fazendo na prática, a gente vai fazendo na prática. (Antunes, E., 2011)

Para a professora Eunice Antunes, a impossibilidade de as novas gerações de guarani terem acesso aos ambientes onde ocorria uma parte significativa da atividade econômica guarani impede o aprendizado da tradição ("não tem um rio próximo para eles estar pescando, caça, não tem como, agricultura, piorou [...] então [...] crescer aprendendo a tradição é difícil"). Esse impedimento acaba fazendo com que os professores assumam como sua a responsabilidade de transmissão da "parte cultural" para os alunos. Esse trabalho para dentro, isto é, a inclusão da cultura guarani como objeto de ensino escolar para os alunos serem mais conscientes dos modos de vida e conhecimentos tradicionais guarani, deve ser complementado com o trabalho de preparação dos alunos "para esse mundo, essa globalização" que chega à aldeia a um ritmo acelerado ("é uma coisa assim que quando a gente percebeu já está na aldeia [...] sem perceber como é que veio"). A professora Eunice verbaliza nessa fala a possibilidade de a escola, elemento desse mundo de fora que invade as aldeias, reverter essa situação para fins não hegemônicos, como divulgar a cultura guarani em contextos não guarani.

Essa visão da professora Eunice é congruente com o posicionamento do professor Marcos, expresso na fala a seguir:

A escola também ela exerce o papel de estar divulgando a cultura lá fora através de vídeo, de fotos, de várias outras coisas que a própria tecnologia nos oferece [...] porque ajuda [...] a mostrar na mídia de que existe um povo guarani, uma comunidade que pensa a cultura, sua história, para estar mostrando lá fora, e com isso também ajuda a sociedade não indígena a dizer assim: "não, lá existe um povo, existe uma comunidade indígena, e merecem todo o respeito, eles têm uma cultura". (Moreira, 2011)

Como é possível arguir com base na fala do professor Marcos, o silenciamento decorrente do pensamento abissal, do qual os indígenas são vítimas paradigmáticas 
(Sousa Santos, 2010) e que tem deslegitimado os Guarani historicamente até torná-los quase invisíveis, faz com que seja ainda hoje necessário "mostrar [...] que existe um povo guarani" e que esse povo "pensa" e "tem" uma cultura e, por isso, "merecem todo o respeito". Esse respeito ainda hoje é negado em decorrência das diferenças dos Guarani em relação ao padrão ocidental de conhecimento e experiência a que a tradição ocidental hegemônica atribui o caráter de universal. A escola, como vemos, também há de exercer a função de "estar divulgando a cultura lá fora" por intermédio do trabalho em diversos meios e suportes ("vídeo, de fotos, de várias outras coisas que a própria tecnologia nos oferece").

Dentro dessa dinâmica de movimentos de dentro para fora e de fora para dentro, a escola constitui uma fronteira ${ }^{9}$ ou "portal" não só para as pessoas e conhecimentos que serão qualificados para sair da aldeia, mas também para aqueles conhecimentos e pessoas que poderão entrar nela. Cabe apontar aqui o espaço central que a escola ocupa hoje nas aldeias como espaço de interação da comunidade com os não indígenas, pois é lá que acontecem inúmeros encontros, reuniões, eventos e semanas culturais, entre outros, que aproximam o universo guarani do universo não indígena, assim como criam laços e pontes (embora, é claro, não exclusivamente) entre os indivíduos de ambos os universos. No que diz respeito ao papel da escola como portal e filtro dos conhecimentos advindos do universo não indígena, o professor Marcos aponta:

A escola, ela é uma peneira dentro da aldeia [...]. Ela é um portal, ou seja, para poder sair lá fora, o Guarani que quer sair para fora, as crianças que estudam, ela vai ter que passar por esse portal que é a escola, e, assim, também o conhecimento de fora para poder passar para a aldeia tem que passar por esse portal. (Moreira, 2011)

Nesse "portal" ou "peneira", no qual transitam bidirecionalmente alunos e conhecimentos, os fluxos de conhecimento hão de convergir em uma tradução de saberes na qual, como sugere Sousa Santos (2004, p. 803), interpretam-se várias culturas com o objetivo de identificar "preocupações isomórficas" e as diferentes respostas que tais culturas oferecem para elas. Leiamos as palavras da professora Eunice Antunes a esse respeito:

Aí, dali para a frente, começar a trabalhar o ensino da língua portuguesa falando em guarani, pegar e contar sobre o livro didático, "olha, na cultura do juru'a, ele fala que isso é isso, e é importante que vocês aprendam; se vocês vão querer sair uma hora, vocês vão estar sabendo que na cultura deles é desse e desse jeito", então estar explicando sobre a cultura do povo juru'a falando em guarani e também contando sobre a nossa cultura, como que é, se tem relação com aquilo, se não tem, qual é. (Antunes, E., 2011)

9 Para se aprofundar na conceitualização de escola indígena enquanto espaço de fronteira, conferir Tassinari (2001). 
Nessa fala da professora Eunice, a tradução entre línguas ("trabalhar o ensino da língua portuguesa falando em guarani”) é representada como havendo de ser paralela à tradução de culturas no sentido de redes de significado. Nessa tradução, os conhecimentos se encontram e se comparam, buscando possíveis relações entre formas de interpretar e representar conhecimentos diversos ("olha, na cultura do juru'a, ele fala que isso é isso [...] e também contando sobre a nossa cultura, como que é, se tem relação com aquilo, se não tem, qual é").

Embora haja uma menção explícita da professora em relação ao livro didático ao se referir à tradução de saberes, as práticas de conhecimento da escola guarani principalmente aquelas nas quais o conhecimento seja (re)constituído dentro da tradição epistemológica guarani - , do ponto de vista dos professores participantes desta pesquisa, precisam ocorrer fora dos limites físicos e epistemológicos do texto escrito, para se materializarem na prática da cultura ("na parte que a gente pode estar fazendo na prática, a gente vai fazendo na prática", afirmou Eunice em uma de suas intervenções, aqui incluída anteriormente). A prática da cultura, dentro do contexto escolar guarani, tal como foi possível identificar em Guerola (2012), diz respeito ao trabalho fora de sala de aula, em ambientes e locais de trabalho mais próximos ou semelhantes àqueles nos quais ocorriam as práticas de conhecimento guarani na anterioridade ao assédio da sociedade, economia e obrigações universais não indígenas, que ainda hoje ocorrem, mas em menor medida. Nesses espaços e práticas, a cultura deixa de ter um caráter preeminentemente discursivo para ter um caráter de ação.

O professor João Batista faz a seguinte consideração a esse respeito:

Hoje em dia tem que ser dentro da sala [de aula] para ver a escrita, também pode praticar assim... na prática, mostrar o que está ensinando também, para isso tem opy, casa de reza, para mostrar a cultura, não adianta só ensinar na escrita e não mostrar nada também, aí os alunos não aprendem, tem que praticar e ensinar na escrita. (Gonçalves, 2011)

$\mathrm{Na}$ visão do professor João Batista, o conhecimento na escola guarani tem que ser (re)constituído em práticas de conhecimento diversificadas. Além das práticas letradas ("Hoje em dia tem que ser dentro da sala [de aula] para ver a escrita"), importam, especialmente, as práticas de conhecimento nos espaços próprios da geração de conhecimento guarani, como a casa de reza (opy), onde a cultura possa ser mostrada e praticada. Somente a combinação de ambos os tipos de práticas de conhecimento na escola, na visão de João Batista, será capaz de garantir a aprendizagem dos alunos ("não adianta só ensinar na escrita e não mostrar nada também, aí os alunos não aprendem, tem que praticar e ensinar na escrita").

O trabalho escolar por meio de práticas de conhecimento nas quais, nos termos guarani, a cultura seja praticada pela ação fora da sala de aula é reivindicado como um direito pelos professores da EIEF Itaty:

Para nós, a gente tem o direito sobre tudo, dar aula em guarani, dar aula na prática, fazer isso, fazer aquilo, do jeito que eu quiser dar aula eu posso dar na prática, eu posso fazer. (Antunes, E., 2011) 
Essa reivindicação do direito à prática da cultura dentro do espaço escolar encontra seu fundamento na dificuldade que os professores guarani têm enfrentado em relação ao não reconhecimento de tal exercício enquanto práticas de conhecimento escolares por parte das instituições oficiais responsáveis pela instrução formal nas aldeias. A instituição da qual depende a EIEF Itaty, a Secretaria de Educação do Estado de Santa Catarina, de acordo com os participantes da pesquisa, nem sempre se tem mostrado aberta a essas práticas pedagógicas.

A Secretaria [Estadual de Educação] até um tempo não aceitava, não entendia essa parte, um professor que levou as crianças lá na casa de reza, fazer a reza, para contar história, ficar lá ao redor do fogo, e chegar aqui [na escola] e não ter professor nem aluno, que aí eles cobravam e era brigar, brigar e discutir com o cacique e com os professores e proibir, "não pode, tem que ficar dentro da sala de aula com o aluno, se não ele vai marcar falta e vai descontar do salário", mas a gente estava dando aula num outro ambiente, numa outra aula, de cultura. (Antunes, A., 2011)

Com base nas palavras do professor Adão Antunes, é possível problematizar o totalitarismo epistemológico que foi trazido à tona na fundamentação teórica deste trabalho. $\mathrm{O}$ exemplo que ele nos traz visibiliza o modo em que uma instituição educativa governamental, valendo-se do pensamento abissal, deslegitima as práticas de conhecimento guarani como ininteligíveis e descartáveis a ponto de buscar proibi-las ("era brigar, brigar e discutir com o cacique e com os professores e proibir"). Do ponto de vista da instituição governamental, apenas as práticas de conhecimento tradicionalmente aprovadas como escolares, de acordo com o padrão de experiência ocidental universal, dentro dos seus espaços e tempos específicos, possuem legitimidade para serem desenvolvidas como parte da carga horária escolar. A legitimidade é exclusiva a ponto de essas práticas serem impostas como uma obrigação ("não pode, tem que ficar dentro da sala de aula com o aluno"). De acordo com o relato de Adão, a desqualificação e a deslegitimação das práticas de conhecimento guarani por parte da instituição oficial seriam tamanhas que os responsáveis por conduzi-las estariam sendo merecedores de punição caso elas fossem desenvolvidas dentro do trabalho escolar ("ele vai marcar falta e vai descontar do salário").

Esse exemplo mostra o modo em que o direito à educação é fundamentado em um imaginário hegemônico que se assenta em "vozes escutadas ou apagadas, [em] memórias compactas ou fraturadas, [em] histórias contadas de um só lado, que suprimiram outras memórias" (Mignolo, 2005, p. 37-38). O silenciamento do significado que o povo guarani atribui à educação e à prática da cultura tem uma repercussão direta na sustentação da hegemonia da epistemologia ocidental por meio de seus espaços e tempos disciplinares, como a sala de aula enquanto organizadora espaço-temporal das práticas de conhecimento institucionais. A imposição de uma lógica de organização espaço-temporal às práticas de conhecimento de uma comunidade constitui uma tentativa de dominação epistemológica, baseada nas extremamente desiguais relações estabelecidas entre epistemologias e conhecimentos com critérios de validade distintos e a serviço de interesses divergentes. 
Apesar das tentativas dos Guarani para terem suas práticas de conhecimento reconhecidas como legítimas pelo sistema de educação oficial, este tem se mostrado hermético em relação às solicitações de professores e comunidades.

A gente bate é na questão do sistema, esse sistema, até a gente fez um documento e mandou perguntar... para o rapaz que trabalha no MEC perguntar "o que que é esse sistema na cabeça de vocês? O que que é isso aí? É uma caixa fechada? Uma caixa redonda que não dá para abrir ali e mudar? O que que é esse sistema?" Esse sistema que para nós é uma coisa tão, tão simples, que, se eu faço alguma coisa e vejo que não está dando certo, [eu] mudo, mas esse sistema é tão fechado! Você manda as coisas lá, ele bate e volta, para as escolas ser do jeito que a comunidade queria, quantos documentos que foram mandados! Ia e numa semana o documento estava aqui porque o sistema não aceitou, mudava de novo, mandava, na outra semana estava aqui porque o sistema não aceitou, daí as lideranças fizeram umas reuniões, "mas que bicho é esse sistema que não muda? Que tipo que é? Eu queria conhecer esse tal do sistema para ver que que é isso!" "Será?” Daí eles falaram: "não, é um computador onde estão guardadas as coisas", "mas joga fora esse computador e pega outro!", aí "ele faz essas coisas sozinho daî", "não, é uma pessoa que fica lâ", "mas, então! A gente quer falar com essa pessoa, vamos ver se essa pessoa muda”. Ah, mas é uma coisa assim que não muda mesmo. (Antunes, E., 2011)

Os professores guarani, assim como seus colegas professores indígenas de outras etnias, "batem na questão do sistema", isto é, na falta de uma atitude receptiva das instituições educativas oficiais e de uma quantidade significativa de seus servidores - por vezes insensíveis às especificidades das culturas e povos indígenas - em relação às demandas ligadas às características próprias da educação indígena na sua hibridização com a escolarização.

$\mathrm{Na}$ fala acima, Eunice chama atenção para a incompreensão quanto ao que seja o sistema ("o que que é esse sistema na cabeça de vocês? O que que é isso aî?" "Eu queria conhecer esse tal do sistema para ver que que é isso!") e sua rigidez e hermetismo ("é uma caixa fechada? Uma caixa redonda que não dá para abrir ali e mudar?", "esse sistema é tão fechado"). Eunice chama atenção também para o insucesso nas tentativas de encaminhamento de documentos a instituições oficiais (no exemplo em questão, ao Ministério da Educação - MEC) por eles não se adequarem aos requerimentos do rígido sistema ("Você manda as coisas lá, ele bate e volta [...] Ia e numa semana o documento estava aqui porque o sistema não aceitou, mudava de novo, mandava, na outra semana estava aqui porque o sistema não aceitou"). Essa rigidez e imutabilidade do sistema é incompreensível para os Guarani ("que bicho é esse sistema que não muda?"), que cada vez tomam maior consciência da impossibilidade desse sistema se abrir às suas demandas e necessidades ("é uma coisa assim que não muda mesmo")

Os professores guarani reivindicam, então, um subsistema específico dentro da rede oficial de educação (no caso que nos ocupa, a rede estadual de educação) que possa dar cabida às demandas relacionadas à educação diferenciada que os Guarani reivindicam para suas escolas. 
Ter a continuidade da língua guarani no ensino médio, nas séries finais do fundamental, isso às vezes acontece, mas é muito pouco, mas isso devido porque a grade curricular muitas vezes não permite isso, por isso que a gente está numa grande batalha com as lideranças também de criar um subsistema de educação escolar indígena para poder dar toda essa ideia que a gente tem de fazer com que aconteça realmente a educação diferenciada também, porque muitas vezes a gente quer mudar para educação diferenciada, mas que o sistema do estado não permite. (Moreira, 2011)

Os obstáculos com que o sistema barra as demandas relacionadas à prática da cultura na escola, aqui levantados anteriormente, estão ligados também às exigências do currículo oficial e à sua grade, a qual às vezes não dá espaço aos conhecimentos e práticas que os Guarani buscam trazer para dentro da escola, segundo a fala de Marcos, por exemplo, àqueles ligados à língua guarani ("a continuidade da língua guarani no ensino médio, nas séries finais do fundamental, [...] a grade curricular muitas vezes não permite"). Um "subsistema de educação escolar indígena" é colocado como alternativa possível para trabalhar na escola dentro da perspectiva de educação diferenciada do padrão oficial que os Guarani buscam para suas comunidades.

Sintetizo nas considerações finais os argumentos levantados para problematizar o direito humano universal à educação, à luz da fundamentação teórica tecida na primeira metade deste trabalho e dos discursos dos professores guarani compilados na análise de dados. Tal síntese argumenta a favor de uma mudança de paradigma em direção a um entendimento desse direito como sendo intercultural à escolarização, indissociável do entendimento da escola enquanto necessidade e obrigação humana, esta sim universal, por ser uma das poucas dissidências possíveis que restam àqueles que gostariam de ter outras alternativas no que diz respeito à sua educação.

\section{VOZES APAGADAS, MEMÓRIAS FRATURADAS E EDUCAÇÃO}

Busquei, ao longo deste texto, problematizar a visão ocidental de educação enquanto direito humano universal, contrapondo-a à visão guarani sobre a escola enquanto direito humano intercultural. $\mathrm{O}$ entendimento do direito à educação como direito humano universal parte de uma visão etnocêntrica de educação, aquela própria do padrão de experiência e conhecimento ocidental, o qual a identifica automaticamente com escolarização, confundindo-as. Se verdades e fundamentos são produtos das comunidades às quais se pertence e da sua história (Vattimo, 2004 apud Souza, 2011), cabe esperar que comunidades com histórias tão diferentes quanto a indígena e a não indígena (e as comunidades incomensuravelmente diversas que se aglutinam dentro delas) elaborem suas verdades e fundamentos com respeito à educação de forma díspar. O direito humano à educação não pode, portanto, ser universal, pois as conceições de educação socialmente aceitas nas diversas partes e comunidades do mundo - muitas das quais não tiveram reconhecida a sua legitimidade a ponto de serem ouvidas para fins de elaboração de declarações universais de direitos humanos - sempre serão inevitavelmente distintas. O direito guarani à educação é o direito à sua compreensão própria do que seja educação e também o seu direito de praticá-la com liberdade e autonomia. 
Porém, em decorrência da impossibilidade de autonomia econômica e política perante o assédio do universo não indígena e a depredação que este faz do meio ambiente, que os torna dependentes da economia de mercado, os Guarani reivindicam o direito intercultural à escolarização, que é um direito recorrente e indissociável da necessidade (uma vez que sem escola não há chance de sobrevivência econômica e luta política) e da obrigação (pois a educação básica é obrigatória por lei). A reivindicação do direito intercultural à escolarização traz no seu bojo outras reivindicações em relação às especificidades da escola, tal qual concebida pelos Guarani para suas aldeias, aos seus objetivos e modos em que acreditam que o trabalho nela deve ser desenvolvido.

A falta de espaços em que se pode ter acesso a essas visões de educação e escola exemplifica o silenciamento e a invisibilização histórica de que os Guarani, e os indígenas em geral, ainda são vítimas. Isso mostra, igualmente, a deslegitimação a esse grupo de suas práticas de conhecimento enquanto ininteligíveis ou descartáveis, a ponto de o sistema educativo institucional buscar proibi-las e censurá-las. É essa a garantia do direito humano à educação? A redução da diversidade epistemológica ao regime disciplinar da sala de aula, a um "bicho" ou uma "caixa fechada" que "não muda mesmo" e não se adapta às especificidades daqueles compulsoriamente necessitados dela?

Com certeza é incauto e irresponsável clamar em contra dos direitos humanos ou da escolarização. Não foi essa a intenção neste trabalho, e sim contribuir para uma maior criticidade em relação ao que seja a educação e os direitos universais a ela vinculados, os quais, quando analisados pela perspectiva das comunidades tradicionalmente silenciadas, deixam transparecer as vozes apagadas e as memórias fraturadas (Mignolo, 2005) em que se assentam, mas que por meio deste texto poderão ser um pouco mais valorizadas.

\section{REFERÊNCIAS}

Antunes, A. Adão Antunes: entrevista [1º nov. 2011]. Palhoça: EIEF Itaty, 2011. Entrevista concedida a Carlos Maroto Guerola.

Antunes, E. Eunice Antunes: entrevista [7 nov. 2011]. Palhoça: EIEF Itaty, 2011. Entrevista concedida a Carlos Maroto Guerola.

Baкhtin, M. The dialogic imagination. Austin: University of Texas Press, 1981.

Brasil. Constituição Federal da República Federativa do Brasil. Brasília, DF: Senado, 1988. Disponível em: <http://www.planalto.gov.br/ccivil_03/constituicao/ constituicaocompilado.htm>. Acesso em: 30 abr. 2015.

Brighenti, C. A. Povos indígenas em Santa Catarina. In: Nötzold, A. L. V.; RosA, H. A.; Bringmann, S. F. (Orgs.). Etnohistória, história indígena e educação: contribuições ao debate. Porto Alegre: Pallotti, 2012. p. 37-65.

Castro-Gómez, S. Ciências sociais, violência epistêmica e o problema da "invenção do outro" In: LANDER, E. (Org.). A colonialidade do saber: eurocentrismo e ciências sociais. Perspectivas latino-americanas. Buenos Aires: CLACSO, 2005. p. 80-87. 
CréPEAU, R. Uma ecologia do conhecimento: é possível? Ilha - Revista de Antropologia, Florianópolis: UFSC, v. 7, n. 12, p. 5-28, 2001.

Dur kheim, É. Pragmatisme et sociologie. Paris: Vrin, 1981.

Escoвar, A. Encoutering development. The Making and Unmaking of the Thirld World. Princeton: Princeton University Press, 1995.

Foucault, M. O sujeito e o poder. In: Rabinow, P.; Dreyfus, H. (Orgs.). Michel Foucault: uma trajetória filosófica - para além do estruturalismo e da hermenêutica. Rio de Janeiro: Universitária, 1995. p. 231-252.

. A ordem do discurso. São Paulo: Loyola, 1996.

Microfísica do poder. [S.1.]: Sabotagem, [200-?].

Geertz, C. The interpretation of cultures: selected essays by Clifford Geertz. New York: Basic Books, 1973.

Gonçalves, J. B. João Batista Gonçalves: entrevista [1º nov. 2011]. Palhoça: EIEF Itaty, 2011. Entrevista concedida a Carlos Maroto Guerola.

Guerola, C. M. Às vezes tem pessoas que não querem nem ouvir, que não dão direito de falar pro indigena: a reconstrução intercultural dos direitos humanos linguísticos na escola Itaty da aldeia guarani do Morro dos Cavalos. 2012. 184p. Dissertação (Mestrado) Universidade Federal de Santa Catarina, Florianópolis, 2012. Disponível em: <http:// www.bu.ufsc.br/teses/PLLG0513-D.pdf>. Acesso em: 25 set. 2017.

Heath, S. B.; Street, B. On ethnography: approaches to language and literacy research. New York: Teachers College Press, 2008.

Hentz, M. I. B. Formando professores indígenas: o direito à língua como ação política. Fórum Linguístico, Florianópolis: UFSC, v. 10, n. 4, p. 279-290, 2013.

Howard-Malverde, R. Creating context in Andean cultures. Oxford: Oxford University Press, 1997.

Ladeira, M. I. (Org.). Resumo do Relatório Circunstanciado de Identificação e Delimitação da Terra Indígena Morro dos Cavalos. Diário Oficial da União, Brasília, DF, 18 nov. 2002, Seção 1, p. 44. Disponível em: <http://www.jusbrasil.com.br/diarios/807560/dou-secao-1-18-12-2002-pg-44>. Acesso em: 20 set. 2017

. Guarani Mbya. Povos indigenas no Brasil. 2003. Disponível em: <http://pib. socioambiental.org/pt/povo/guarani-mbya>. Acesso em: 30 abr. 2015.

Lander, E. (Org.). A colonialidade do saber: eurocentrismo e ciências sociais. Perspectivas latino-americanas. Buenos Aires: CLACSO, 2005a.

. Ciências sociais: saberes coloniais e eurocêntricos. In: LANDER, E.(Org.). A colonialidade do saber: eurocentrismo e ciências sociais. Perspectivas latino-americanas. Buenos Aires: CLACSO, 2005b. p. 8-23.

Leite, L. H. Á. La educación intercultural bilingüe: el caso brasileño. Buenos Aires: Fundación Laboratorio de Políticas Públicas, 2008.

Litaiff, A. As divinas palavras: identidade étnica dos Guarani-Mbya. Florianópolis: Editora da UFSC, 1996. 
Litaiff, A.; Darella, M. D. P. Os índios Guarani Mbya e o Parque Estadual da Serra do Tabuleiro. In: Reuniño Brasileira de Antropologia, 22., 2000, Brasília. Anais... Brasília: Associação Brasileira de Antropologia, 2000.

MeEk, R. Los orígenes de la ciencia social: el desarrollo de la teoría de los cuatro estadios. Madri: Siglo XXI, 1981.

Mignolo, W. D. Os esplendores e as misérias da "ciência": colonialidade, geopolítica do conhecimento e pluri-diversidade epistémica.In: Sousa Santos, B. (Org.). Conhecimento prudente para uma vida decente: um discurso sobre as ciências, revisitado. São Paulo: Cortez, 2004. p. 667-709.

. A colonialidade de cabo a rabo: o hemisfério ocidental no horizonte conceitual da modernidade. In: LANDER, E. (Org.). A colonialidade do saber: eurocentrismo e ciências sociais. Perspectivas latino-americanas. Buenos Aires: CLACSO, 2005. p. 33-49.

Moreira, M. Marcos Moreira: entrevista [31 out. 2011]. Palhoça: EIEF Itaty, 2011. Entrevista concedida a Carlos Maroto Guerola.

Oliveira, R. C. A sociologia do Brasil indígena. Rio de Janeiro: Tempo Brasileiro, 1972. Qujuano, A. Colonialidad del poder, cultura y conocimiento en América Latina. In: Castro-Gómez, S.; Guardiola-Rivera, O.; Millán de Benavides, C. (Eds.) Pensar (en) los interticios: teoría y práctica de la crítica poscolonial. Bogotá: CEJA, 1999.

Rosa, H. A. A trajetória histórica da escola na comunidade Guarani de Massiambu, Palhoçal $S C$ : um campo de possibilidades. 2009. 165p. Dissertação (Mestrado em História) Universidade Federal de Santa Catarina, Florianópolis, 2009.

Salvaro, T. D. De geração em geração e o lápis na mão: o processo de revitalização da língua kaingang na educação escolar indígena/Terra Indígena Xapecó - SC. 2009. 170p. Dissertação (Mestrado em História) - Universidade Federal de Santa Catarina, Florianópolis, 2009.

Santos, S. C. Educação e sociedades tribais. Porto Alegre: Movimento, 1975.

. Os poros indígenas e a Constituinte. Florianópolis: EdUFSC; Movimento, 1989.

Schaden, E. Aspectos fundamentais da cultura guarani. São Paulo: EPU; EDUSP, 1974.

Sousa Santos, B. Poderá o direito ser emancipatório? Revista Crítica de Ciências Sociais, Coimbra: Universidade de Coimbra, n. 65, p. 3-76, maio 2003.

.Para uma sociologia das ausências e uma sociologia das emergências. In: SousA Santos, B. (Org.). Conhecimento prudente para uma vida decente: um discurso sobre as ciências, revisitado. São Paulo: Cortez, 2004. p. 777-821.

. Descolonizar el saber, reinventar el poder. Montevideu: Trilce, 2010.

Sousa Santos, B.; Meneses, M. P. Introdução. In: Sousa Santos, B.; Meneses, M. P. (Orgs.). Epistemologias do Sul. São Paulo: Cortez, 2010. p. 15-27.

Souza, L. M. T. M. Relatório sobre Educação Indígena Diferenciada, Intercultural e Bilíngue no Brasil. In: López, L. E.; Hanemann, U. (Orgs.). Alfabetización y multiculturalidad: miradas desde América Latina. Guatemala: UIL/UNESCO; PACEGTZ, 2009. p. 99-128. 
SouzA, L. M. T. M. Cultura, língua e emergência dialógica. Letras $\Xi^{\circledR}$ Letras, Uberlândia: UFU, v. 26, n. 2, p. 289-306, jul./dez. 2010.

.Para um redefinição de letramento crítico: conflito e produção de significação. In: Maciel, R. F. ; Araujo, V. A. (Orgs.). Formação de professores de línguas: ampliando perspectivas. Jundiaí: Paço Editorial, 2011.

Tassinari, A. M. I. Escola indígena: novos horizontes teóricos, novas fronteiras da educação. In: Silva, A. L.; Ferreira, M. K. L. (Orgs.).Antropologia, história e educação: a questão indígena e a escola. São Paulo: Global, 2001. p. 44-69.

Tedlock, D., Mannheim, B. (Eds.). The dialogic emergence of culture. Urbana: University of Illinois Press, 1995.

Vatтimo, G. Nibilism and emancipation: ethics, politics and the law. New York: Columbia University Press, 2004.

Vieira, I. F. Educação escolar indígena: as vozes guarani sobre a escola na aldeia. 2006. 183p. Dissertação (Mestrado em Educação) - Universidade Federal de Santa Catarina, Florianópolis, 2006.

\section{SOBRE O AUTOR}

Carlos Maroto Guerola é doutor em linguística pela Universidade Federal de Santa Catarina (UFSC). Professor da mesma instituição.

E-mail: cmguerola@gmail.com

Recebido em 30 de abril de 2015

Aprovado em 18 de agosto de 2015 